\title{
Knowledge Assessment of the Dental Healthcare Workers Regarding Sterilization Integrity of Dental Instruments
}

\author{
Ali AlAhdal ${ }^{1, *}$, Rawiah Bahlas ${ }^{2}$, Ammar Mahfouz $^{3}$, Esraa AlAhdal ${ }^{4}$, Khalid Aboalshamat ${ }^{5}$ and Atef Shibl ${ }^{6}$ \\ ${ }^{1}$ Dentist, Infection Preventionist, Planning and Research Directorate, Makkah Health Affairs, MOH, Saudi Arabia \\ ${ }^{2}$ Infection control practitioner, Department of Infection Control, King Abdulaziz University Hospital, Jeddah, Saudi Arabia \\ ${ }^{3}$ Consultant in Advanced Restorative Dentistry and Dental Implant, King Fahad Armed Forces Hospital, Jeddah, Saudi Arabia \\ ${ }^{4}$ Staff dentist, Ministry of National Gaurd, Taif Primary Healthcare Clinic, Saudi Arabia \\ ${ }^{5}$ Dental Public Health Division, Preventive Dentistry Department, College of Dentistry, Umm Al-Qura University, Makkah, Saudi Arabia \\ ${ }^{6}$ Department of Immunology and Microbiology, Alfaisal University, Riyadh, Saudi Arabia
}

*Corresponding author: Ali AlAhdal, Dentist, Infection Preventionist, Planning and Research Directorate, Makkah Health Affairs, MOH, Saudi Arabia, Tel: +966567572600; E-mail: ali-alahdal10@hotmail.com

Received: 15 May, 2019 | Accepted: 31 May, 2019 | Published: 06 Jun, 2019

Citation: AlAhdal A, Bahlas R, Mahfouz A, AlAhdal E, Aboalshamat K, et al. (2019) Knowledge Assessment of the Dental Healthcare Workers Regarding Sterilization Integrity of Dental Instruments. Int J Dent Oral Health 5(4): dx.doi.org/10.16966/2378-7090.297

Copyright: (C) 2019 AlAhdal A, et al. This is an open-access article distributed under the terms of the Creative Commons Attribution License, which permits unrestricted use, distribution, and reproduction in any medium, provided the original author and source are credited.

\begin{abstract}
Background and objectives: Sterilization process has been considered as an integral part of the infection prevention and control measures in dental clinics. The primary objective of this study is to assess the knowledge of the dental healthcare workers related sterilization integrity of autoclaved dental instruments.
\end{abstract}

Methodology: A cross-sectional study was conducted by the use of a structured, self-administered questionnaire that has been sent through the Saudi Dental Society's e-mail database.

Results: The study included 680 participants and 224 responded to the questionnaire (32.9\%). Only $4.5 \%$ have responded correctly to the questionnaire. $67.3 \%$ have written and accessible policy and procedures related to instruments' sterilization and $60.5 \%$ have not attended training sessions related to sterilization. The statistical analysis showed a significant association with working in the governmental facility and attending training sessions in sterilization $(p<0.05)$. Participants who have infection control policy in their institution have significantly higher knowledge.

Conclusion: The study indicates insufficient knowledge of the dental healthcare workers related to maintenance of sterilization integrity of the autoclaved dental instruments.

Keywords: Sterilization education; Sterilization integrity; Dental infection control; Dental sterilization

\section{Introduction}

Infection prevention and control (IPC) science can be defined as a set of measures based on scientific evidence which are implemented into the environment and through practical procedures aiming to inhibit and manage the spread, acquisition and cross of infectious agents within the healthcare facility to protect the patients as well as the healthcare providers and their relatives from the harmful effects of the microorganisms. The ultimate goal for the implementation of IPC instructions is to offer a safe biological environment for the medical practices by breaking the chain of infection. These medical practices might negatively influence the patient's safety during healthcare services if the IPC instruction is not carefully followed.

The subject of infection control in dentistry has aroused much controversy and debate during the past decade especially since 1978 to prevent hepatitis B infections [1]. Then, more attention to the subject of infection control in the field has been brought to the surfaces as a result of the global spread of the human immunodeficiency virus infection since 1983. Thus, some regulatory bodies have announced guidelines for infection control in dentistry and the current agreement among them stated that every dental patient should be considered infectious. This unified agreement was decided because of the asymptomatic carriage of pathogens due to the sub-clinical nature, the prodromal period and the carrier state associated with some diseases. The universal infection control rules should encompass six elements: routine patient evaluation, personal protection with barrier techniques, instrument sterilization including sterilization control, surface and equipment disinfection, asepsis in the laboratory and appropriate disposal of contaminated waste including sharps. In the end, practitioners should attempt to keep high compliance of the rules 
and regulations related to the subject of infection control in dentistry which are continuously improving due to the rapidly enlarging data pool on infectious diseases and their modes of prevention [2].

Sterilization is one well-recognized procedure for microbial control and considered a valuable asset in achieving the goal of IPC as part of microbial control methods in healthcare (Figure 1). Cleaning instruments that don't contain lumen is a direct, precise procedure and rarely leaves residual bioburden on their surfaces. Though, it is also considered a critical step for sterilization and disinfection because they commonly contain serrated handles $[3,4]$. The result of instruments reprocessing is dependable on the knowledge, orientation and qualification of the staff [5]. Here, there is a difficulty determining the failure in the sterilization process because it is hard for their naked eye to address the actual problem. Therefore, it is always essential to use different types of monitoring tools such as the internal $\mathrm{Cls}$, as they help in detecting the sterilization failure related to the faulty loading, improper packaging or sterilizer malfunction. Active continuous quality control process in addition to the staff competency to the policies of IPC along with consistent proper use are all essential sterilization monitoring tools [6].

Maintaining sterilization integrity of the instruments in their pouches after reprocessing is dependent on multiple factors starting with the cleaning and decontamination until they are being used. These are considered all or none factors. According to the Center for Disease Control and Prevention's (CDC) guideline for disinfection and sterilization, 2008 guideline, instruments should meet specific criteria to be considered sterilized in their packages at the point of use after completion of the sterilization cycle. These include securely sealed, unbroken and completely dry without any sign of wetting or moisture packages. Moreover, there should be no sign of rust or change in color of both the instrument $\&$ the package. The criteria also include proper use of internal chemical indicators (CIs) which should match the same type of sterilization method and should be positioned to be visible from outside the package. Furthermore, their interpretation should follow manufacturer's instructions. This study will investigate the knowledge of the dental healthcare workers (DHWs) related to sterilization integrity of autoclaved dental instruments.

\section{Methodology}

This is an analytical cross-sectional study in which a survey has been conducted among a non-randomized purposive sample where the total population was included. The questionnaire consisted of three parts:

Part 1) Sociodemographic data of the participants

Part 2) Assess their training and work experience

Part 3) Assess the level of knowledge for DHWs

The $3^{\text {rd }}$ part was structured to invistigate the knowledge of the DHWs against the CDC critria for determination of sterilization intigrity. Seven statements were put in this section with three optional answers (agree, disagree and I don't know). Scoring system of which 1 $=$ correct respons and $0=$ incorrect respons was followed. Responses which included "I don't know" will be considered as an incorrect responses.

The total population of the research included all governmental and private employees in the field of dentistry in Makkah city who are registered in the database of the Saudi Dental Society (SDS). A total number of $680 \mathrm{DHWs}$ were surveyed. The target response rate was determined as $246(206-280)$ DHWs by using estimate proportions at 95\% confidence level with 5\% marginal error and assuming that 50\% of the DHWs were expected to have the right knowledge. The system of the SDS could avoid any duplication.

The study was completed by the use of a structured, selfadministered questionnaire in the English language through the email of the DHWs which are registered in the SDS over the period from August to October 2017. The email was sent repeatedly over six periods with 2-weeks interval during the three months. Data was transferred electronically from excel to IBM SPSS Statistics 24 and statistical analysis was conducted. The descriptive analysis of the quantitative data was presented using frequencies and percentages. Other statistical analyses were used (t-test and ANOVA). Ethical Approval was obtained prior to conduct the study (Alfaisal University, IRB 65-18).

\section{Validity and Reliability}

Three types of validity were used in this study:

1. Face validity: in which a professional opinion was taken about the questionnaire.

2. Content validity: a pilot study has been conducted over 20 candidates and their feedback was obtained. Modification to the questionnaire form was then implemented accordingly.

3. Criterion validity: each point in part three of the questionnaire represents a single criterion for maintaining sterilization integrity in the CDC guideline.

The reliability was tested in the study using Internal Consistency Reliability which is used to assess the consistency of results across items within a test by two different statements for the same criteria and chick how the participants responded to them. Also, the Cronbach's alpha was used and scored (0.62) to assess the reliability of the knowledge part.

\section{Statistical Analysis and Results}

A total of 223 participants were involved in the current study with a mean age of 34.26 years and standard deviation of 6.98. Participants' demographic variables are displayed in table 1.

Table 2 shows the participants' responses as related to their training experience, their answers regarding the presence of IPC policy, attending on-job IPC training, and attending IPC undergraduate training.

The average knowledge was compared among different participants' institute, gender, level of education, nationality, specialty, and training experience using t-test and ANOVA. These comparisons are displayed in table 3. Participants score mean was $4.19(\mathrm{SD}=1.59)$ for the correct responses out of seven knowledge questions. Only 10 (4.5\%) participants were able to respond to all the seven correctly. Table 3 shows the association between the different variable and the mean score of the knowledge of the DHWs.

Linear regression test showed that the total knowledge score was not significantly related to participants' age ( $\mathrm{p}$-value $=0.057$ ) or year of experience $(\mathrm{p}$-value $=0.093)$.

\section{Discussion}

Our study aimed to investigate the knowledge of the dental healthcare workers related to sterilization integrity of autoclaved dental instruments.Around the globe, studies have been conducted to address the awareness level and practice of the DHWs regarding the methods of sterilization. However, to the best of the knowledge of the authors, they have not addressed the knowledge of the DHWs in maintaining sterilization integrity of the instruments after the sterilization process at the point of use. 
Table 1: Participants' demographic data.

\begin{tabular}{|c|c|c|c|}
\hline \multirow{2}{*}{ Institute } & Governmental & Count & $\%$ \\
\cline { 2 - 4 } & Private & 179 & 80.30 \\
\hline \multirow{2}{*}{ Gender } & Male & 44 & 19.70 \\
\cline { 2 - 4 } & Female & 120 & 53.80 \\
\hline \multirow{3}{*}{$\begin{array}{c}\text { Level of } \\
\text { Education }\end{array}$} & diploma & 103 & 46.20 \\
\cline { 2 - 4 } & bachelor & 125 & 13.50 \\
\cline { 2 - 4 } & master & 30 & 13.50 \\
\hline \multirow{2}{*}{\begin{tabular}{c} 
Nationality \\
\cline { 2 - 4 }
\end{tabular}} & PhD/ Board & 38 & 17.00 \\
\cline { 2 - 4 } & Saudi & 43 & 190.70 \\
\hline \multirow{2}{*}{$\begin{array}{c}\text { Specialty (please } \\
\text { specify) }\end{array}$} & non-Saudi & 34 & 15.20 \\
\cline { 2 - 4 } & non-invasive specialties & 147 & 65.90 \\
\cline { 2 - 4 } & dental assistant or & 42 & 18.80 \\
\hline
\end{tabular}

Table 2: Participants' responses to the presence of IPC policy and their IPC training experience.

\begin{tabular}{|c|c|c|c|}
\hline \multicolumn{2}{|c|}{} & Count & Column N \% \\
\hline \multirow{2}{*}{ Presence of IPC policy } & Yes & 150 & 67.30 \\
\cline { 2 - 4 } & No & 36 & 16.10 \\
\cline { 2 - 4 } & I do not know & 37 & 16.60 \\
\hline \multirow{3}{*}{$\begin{array}{c}\text { On-job training attendance } \\
\text { Undergraduate training }\end{array}$} & Yes & 88 & 39.50 \\
\cline { 2 - 4 } attendance & No & 135 & 60.50 \\
\cline { 2 - 4 } & Yes & 144 & 64.60 \\
\hline \multirow{2}{*}{$\begin{array}{c}\text { Und } \\
\text { No }\end{array}$} & 79 & 35.40 \\
\hline
\end{tabular}

Table 3: Comparison of participants' total knowledge regarding CDC's criteria of sterilization integrity.

\begin{tabular}{|c|c|c|c|}
\hline \multirow{2}{*}{\multicolumn{2}{|c|}{ Independent Variables }} & \multicolumn{2}{|c|}{ Results } \\
\hline & & \multirow{2}{*}{$\begin{array}{c}\text { Knowledge } \\
\text { Mean }\end{array}$} & \multirow{2}{*}{$\begin{array}{c}\text { Standard } \\
\text { Deviation } \\
1.47\end{array}$} \\
\hline Inctituto & Governmental & & \\
\hline Institute & Private & 3.57 & 1.9 \\
\hline \multirow{2}{*}{ Gender } & Male & 4.33 & 1.59 \\
\hline & Female & 4.03 & 1.58 \\
\hline \multirow{4}{*}{ Level of Education } & diploma & 4 & 1.72 \\
\hline & bachelor & 4.23 & 1.65 \\
\hline & master & 3.93 & 1.44 \\
\hline & PhD/ Board & 4.42 & 1.43 \\
\hline \multirow{2}{*}{ Nationality } & Saudi & 4.29 & 1.49 \\
\hline & non-Saudi & 3.79 & 1.95 \\
\hline \multirow{3}{*}{$\begin{array}{l}\text { Specialty (please } \\
\text { specify) }\end{array}$} & $\begin{array}{c}\text { invasive } \\
\text { specialties }\end{array}$ & 4.26 & 1.68 \\
\hline & $\begin{array}{l}\text { non-invasive } \\
\text { specialties }\end{array}$ & 4.18 & 1.55 \\
\hline & $\begin{array}{c}\text { dental assistant } \\
\text { or hygienist }\end{array}$ & 4.19 & 1.71 \\
\hline \multirow{3}{*}{$\begin{array}{c}\text { Presence of IPC } \\
\text { policy }\end{array}$} & Yes & $4.48 * *$ & 1.39 \\
\hline & No & 3.78 & 1.85 \\
\hline & I do not know & 3.43 & 1.79 \\
\hline \multirow{2}{*}{$\begin{array}{l}\text { On-job training } \\
\text { attendance }\end{array}$} & Yes & $4.73^{*}$ & 1.39 \\
\hline & No & 3.84 & 1.62 \\
\hline \multirow{2}{*}{$\begin{array}{l}\text { Undergraduate } \\
\text { training session }\end{array}$} & Yes & 4.22 & 1.45 \\
\hline & No & 4.14 & 1.83 \\
\hline
\end{tabular}

$* p<0.05, * *$ Participants who have IPC policy in their institution have significantly higher knowledge than those who do not, or the participants who do not know about the presence of a policy.

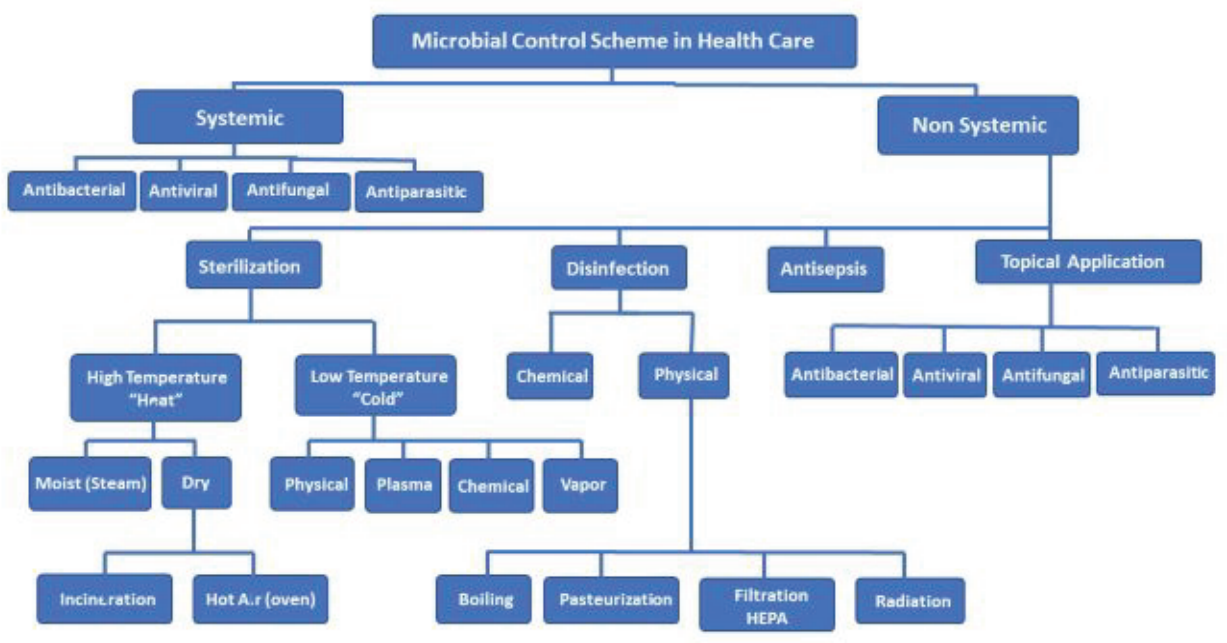

Figure 1: Microbial control methods in healthcare facilities. 
Many dental instruments are used to penetrate the sterile tissues of the oral cavity which give a direct access to the pthogenic microorganism. The risk of cross infection increases if the IPC measures are not strictly followed. Therfore, it is mandatory to use dental instruments that are properly sterilized.

During five acute HBV cluster investigation in West Virginia at 2009, the investigators revealed many infection control breaches involved sterilization of the dental instruments. Volunteer staff were responsible for the decontamination process. These breaches included improper delination of dirty and clean areas,unrapped sterilization of the instruments, and no CIs were used. Hanpieces and intra oral mirors were only wiped with disinfectant from their outer surfaces without sterilization between patients [7]. Despite the rare transmission of the blood-bourne pathogens in the dental practice, the sequel of such event is not appreciated.

The IPC department in the ministry of health in Saudi Arabia has provided the hospitals with clear IPC policies related to the CSSD and dental centers/department which include instructions for maintaining sterility of already sterilized instruments. Surprisingly, only 10 (4.5\%) of the participants have the full knowledge [8].

DHWs who works in governmental facilities tend to have a significant higher knowledge mean than those who are working for private sector. Such finding might be explained by the continuous professional auditing and the presence of policies related to IPC and sterilization. However, as compared to the percentage of the participants $(68.29 \%)$ who have written and accessible policy and procedures related to instruments' sterilization, yet the correct responses are deficient. It is most probably due to incomplete policy information, or the participants have not read the policies in case the full information is there. Also, the results show that $123(60 \%)$ of the participants have not attended training sessions related to sterilization. Therefore, their knowledge might not be as expected.

The culture of practicing IPC in the dental clinic started mainly at the dental school. During the undergraduate dental training, teaching the essence of IPC might affect the outcome of the future dentists' knowledge and attitude. At the University of Birmingham, Milward and Cooper investigated the outcome of an integrated pre-clinical IPC program for the undergraduate students. They concluded that the incorporated competency program in IPC significantly influenced the students' knowledge and practice [9]. Our data revealed that $63.9 \%$ had received formal training in infection control and dental sterilization during their undergraduate studies. On the other hand, low knowledge score concerning sterilization integrity most commonly imposed sketchy training program. That percentage is lower than of the DHWs working in Hail region, Saudi Arabia [10]. Nevertheless, the study in Hail did only look for the compliance with using sterilization methods in dental clinics.

Attended training sessions related to sterilization is a significant factor as a source of knowledge for most of the tested criteria. It indicates the importance of the continuous educational sessions to increase the awareness and update the knowledge of the healthcare workers. In 2012, Bailey et al. published a study which evaluated the impact of taught disinfection and decontamination course. They assessed the pre-and post-course knowledge of the dental postgraduates. The study concluded that the continuous educational programs significantly enhanced the knowledge of the dental professionals towards disinfection and decontamination processes [11]. This was also reported and emphasized to be effective through a quality improvement project [12].

\section{Conclusions}

There is a deficiency in the knowledge of the DHWs regarding maintaining sterilization integrity of autoclaved dental instruments. Presence of policy related to sterilization and attending on-job training sessions play an important role in increasing their knowledge.

\section{Recommendations}

1) The administration should pay more attention to the implementation of sterilization process and coordinate with other entities to provide training sessions in the sterilization process and maintaining sterilization integrity.

2) The facilities should revise and construct policies that are related to sterilization and sterile products.

3) More focus on the independent facilities such as private dental clinics and primary healthcare centers.

\section{Limitations of the Study}

This study is limited to Makkah city and the results can't be generalized to other areas. However, our research creates a paradigm for researchers and colleagues. Further investigations are required to discover the level of knowledge of the DHWs regarding the sterilization integrity in different regions.

\section{References}

1. Molinari JA (2016) Infection Control $Q$ and A: Instrument processing. RDH 36: 60-61.

2. Samaranayake L (1993) Rules of infection control. Int Dent J 43: 578584.

3. Rutala WA, Gergen MF, Jones JF, Weber DJ (1998) Levels of microbial contamination on surgical instruments. Am J Infect Control 26: 143145.

4. Chan-Myers H, McAlister D, Antonoplos P (1997) Natural bioburden levels detected on rigid lumened medical devices before and after cleaning. Am J Infect Control 25: 471-476.

5. Gilmour D (2008) Instrument Integrity and Sterility: The Perioperative Practitioners Responsibilities. J Perioper Pract 18: 292-296.

6. Seavey R (2016) Troubleshooting failed sterilization loads: Process failures and wet packs/loads. Am J Infect Control 44 : e29-e34.

7. Radcliffe RA, Bixler D, Moorman A, Hogan VA, Greenfield VS, et al. (2013) Hepatitis B virus transmissions associated with a portable dental clinic, West Virginia, 2009. J Am Dent Assoc 144: 1110-1118.

8. Ministry of Health (2018) Manual of Infection Prevention \& Control in Dental Settings. $2^{\text {nd }}$ Edition. Saudi Arabia.

9. Milward MR, Cooper PR (2007) Competency assessment for infection control in the undergraduate dental curriculum. Eur J Dent Educ 11: 148-154.

10. Haridi HK, Al-Ammar AS, Al-Mansour MI (2016) Compliance with infection control standard precautions guidelines: a survey among dental healthcare workers in Hail Region, Saudi Arabia. J Infect Prev 17: 268-276.

11. Bailey SER, Wilson MJ, Griffiths R, Bullock AD, Cowpe JG, et al. (2012) Continuing dental education: evaluation of the effectiveness of a disinfection and decontamination course. Eur J Dent Educ 16: 59-64.

12. Tamilselvi M, Srinivas A (2016) Clinical Quality Strategy Facilitates Effective Quality System Implementation for Prevention of Healthcare Associated Infections. Management in Health. 